\title{
Effect of nitrogen source and acclimatization on specific growth rates of microalgae determined by a high throughput in vivo microplate autofluorescence method
}

Podevin, Michael Paul Ambrose; De Francisci, Davide; Holdt, Susan Løvstad; Fotidis, loannis; Angelidaki, Irini

Publication date:

2017

Document Version

Publisher's PDF, also known as Version of record

Link back to DTU Orbit

Citation (APA):

Podevin, M. P. A., De Francisci, D., Holdt, S. L., Fotidis, I., \& Angelidaki, I. (2017). Effect of nitrogen source and acclimatization on specific growth rates of microalgae determined by a high throughput in vivo microplate autofluorescence method.

\section{General rights}

Copyright and moral rights for the publications made accessible in the public portal are retained by the authors and/or other copyright owners and it is a condition of accessing publications that users recognise and abide by the legal requirements associated with these rights.

- Users may download and print one copy of any publication from the public portal for the purpose of private study or research.

- You may not further distribute the material or use it for any profit-making activity or commercial gain

- You may freely distribute the URL identifying the publication in the public portal 


\section{Effect of nitrogen source and acclimatization on specific growth rates of microalgae determined by a high throughput in vivo microplate autofluorescence method}

Michael Podevin ${ }^{1,3}$ • Davide De Francisci ${ }^{1}$ Susan L. Holdt ${ }^{1,2}$ • Ioannis Fotidis ${ }^{1}$ - Irini Angelidaki ${ }^{1}$

${ }^{1}$ Department of Environmental Engineering, Technical University of Denmark, Building 113, DK-2800 Kgs. Lyngby, Denmark

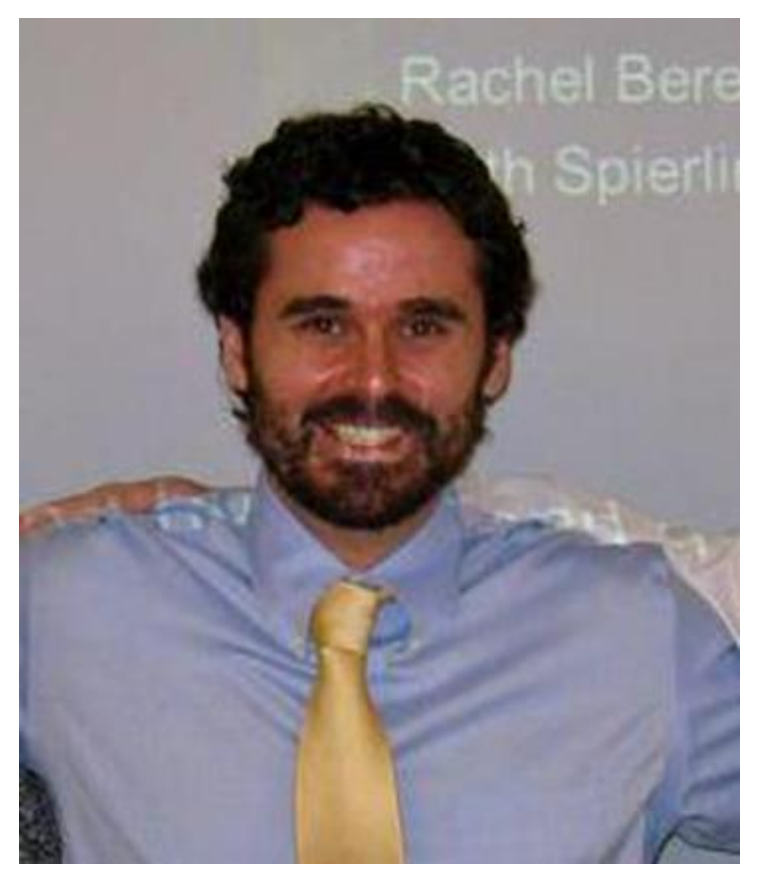

${ }^{2}$ Current address: Susan L. Holdt: National Food Institute, Technical University of Denmark, Søltofts Plads 221, DK-2800 Kgs. Lyngby, Denmark

E-mail: mipp@env.dtu.dk

\section{Abstract}

\section{Aims}

Specific growth rates (SGR) of fresh water algal strains (Chlorella vulgaris, Auxenochlorella protothecoides, and Chlorella sorokiniana) and the marine strain Nannochloropsis oculata on various nitrogen sources (ammonium carbonate, ammonium chloride, sodium nitrate, and urea) could be determined by in vivo chlorophyll-a autofluorescence. These preferences could be determined before large $\mathrm{pH}$ changes occurred in the media, with no significant difference $(P>0.05)$ between buffered and non-buffered media. In all algal species, acclimatization was observed with no significant difference $(P$ $>0.05$ ) between SGRs of second and third cultivations. ANOVA of SGRs in the acclimatized second and third cultivation revealed preferences for nitrogen sources among most of the algae; $C$. vulgaris preferred sodium nitrate over other nitrogen sources, $A$. protothecoides adapted to urea after no growth in the first cultivation, and the SGRs of $N$. oculata showed an aversion for sodium nitrate over other nitrogen sources $(P<0.05)$

\footnotetext{
- Developing a microplate screening technique for high throughput screenings of microalgae.

- to determine the preference of nitrogen source for algal growth for four industrially important microalgae

- Determine the acclimatized SGR of each algae species to each nitrogen source.

- Determine the SGR before large changes in pH occur.
}

\section{ether nitogen sources $(P<0.05)$.}

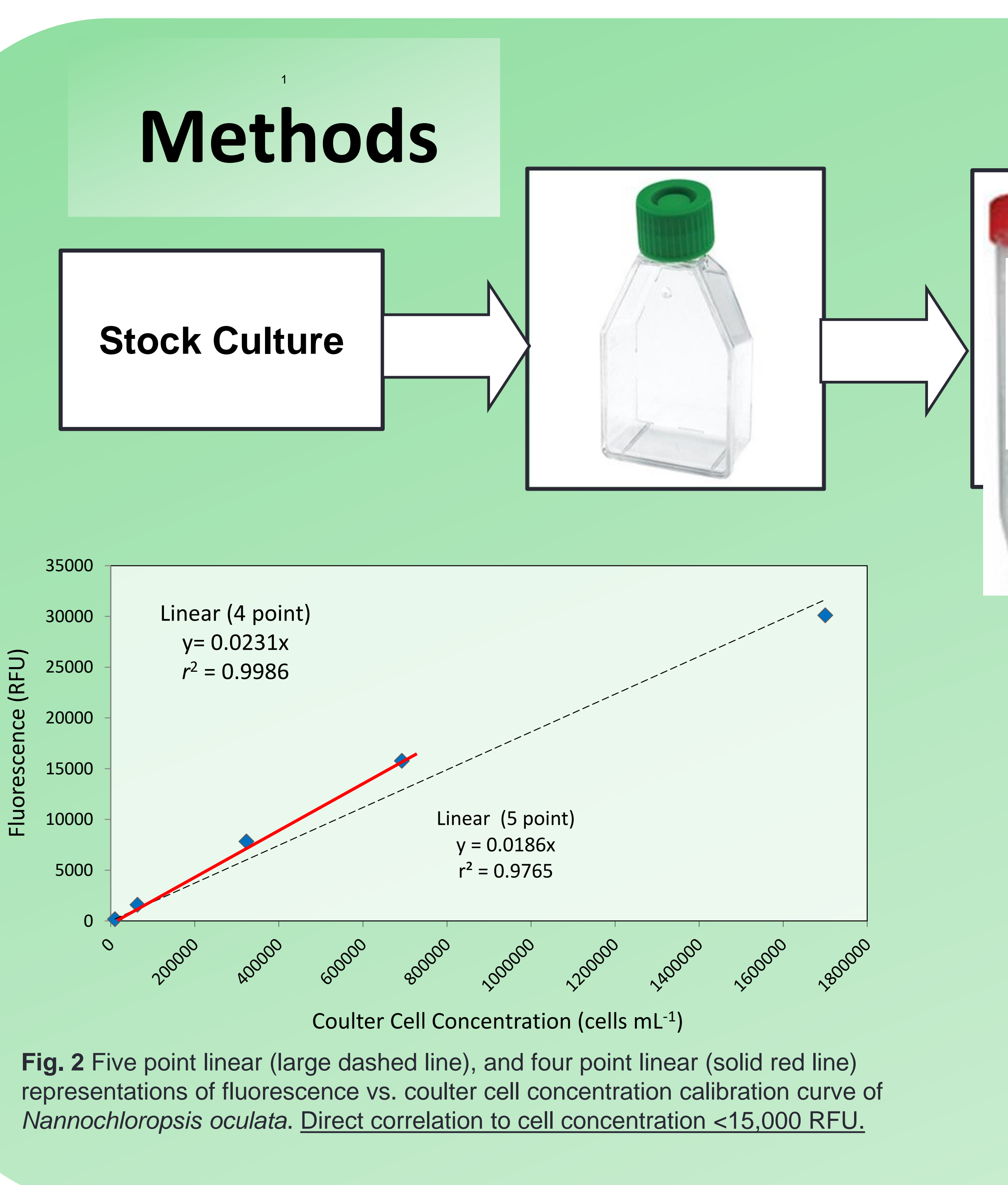

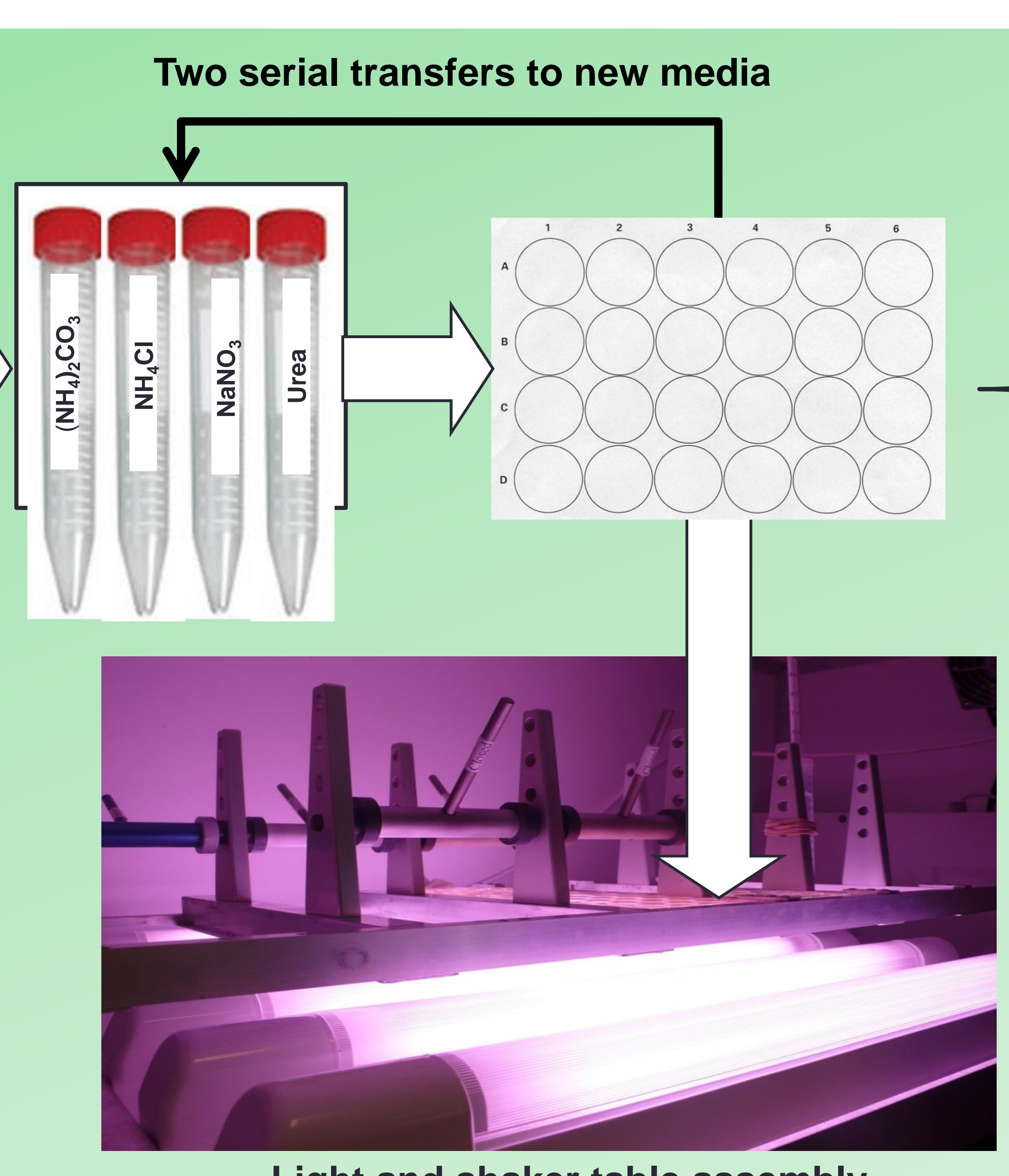

Light and shaker table assembly

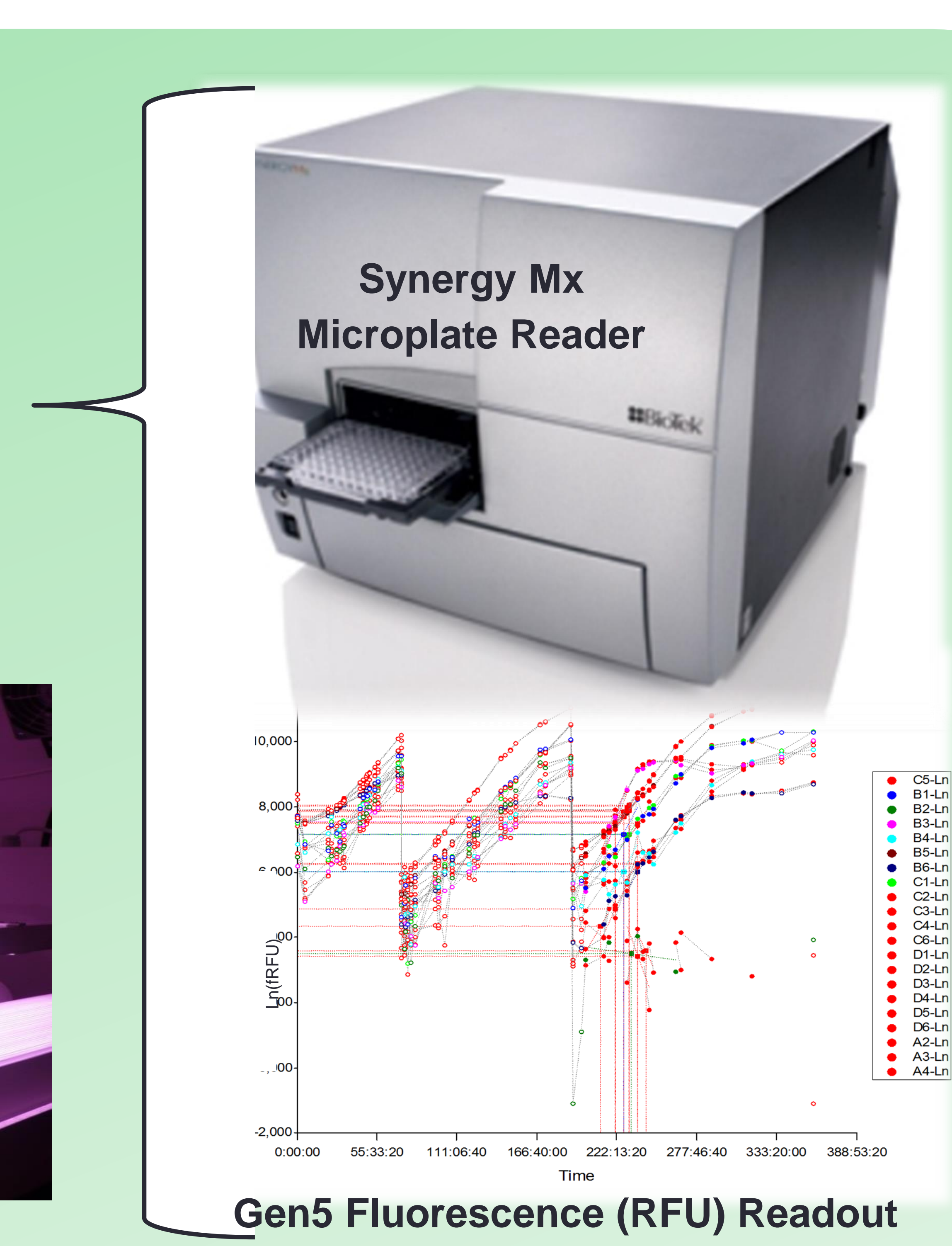

Gen5 Fluorescence (RFU) Readout

\section{Results}

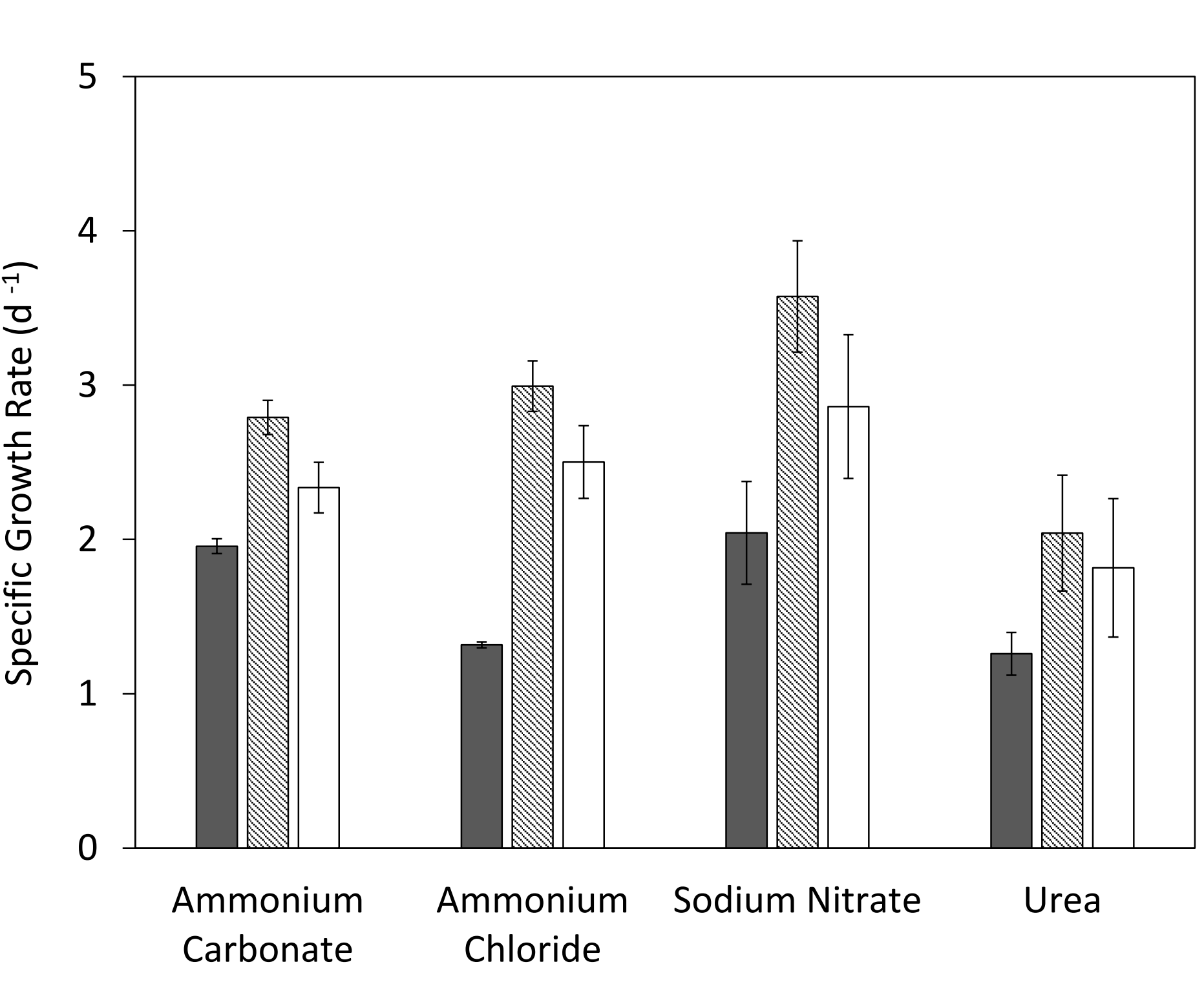

Fig. 4 Specific growth rate (day ${ }^{-1}$ ) of a) Chlorella.vulgari,s b) Auxenochlorella protothecoides), c) Chlorella

sorokiniana, and d) Nannochloropsis oculata grown over three generations on the four different nitrogen sources (ammonium carbonate, ammonium chloride, sodium nitrate, and urea). The nitrogen source concentration was $1 \mathrm{M}$ nitrogen. Note different scale of $y$-axis.

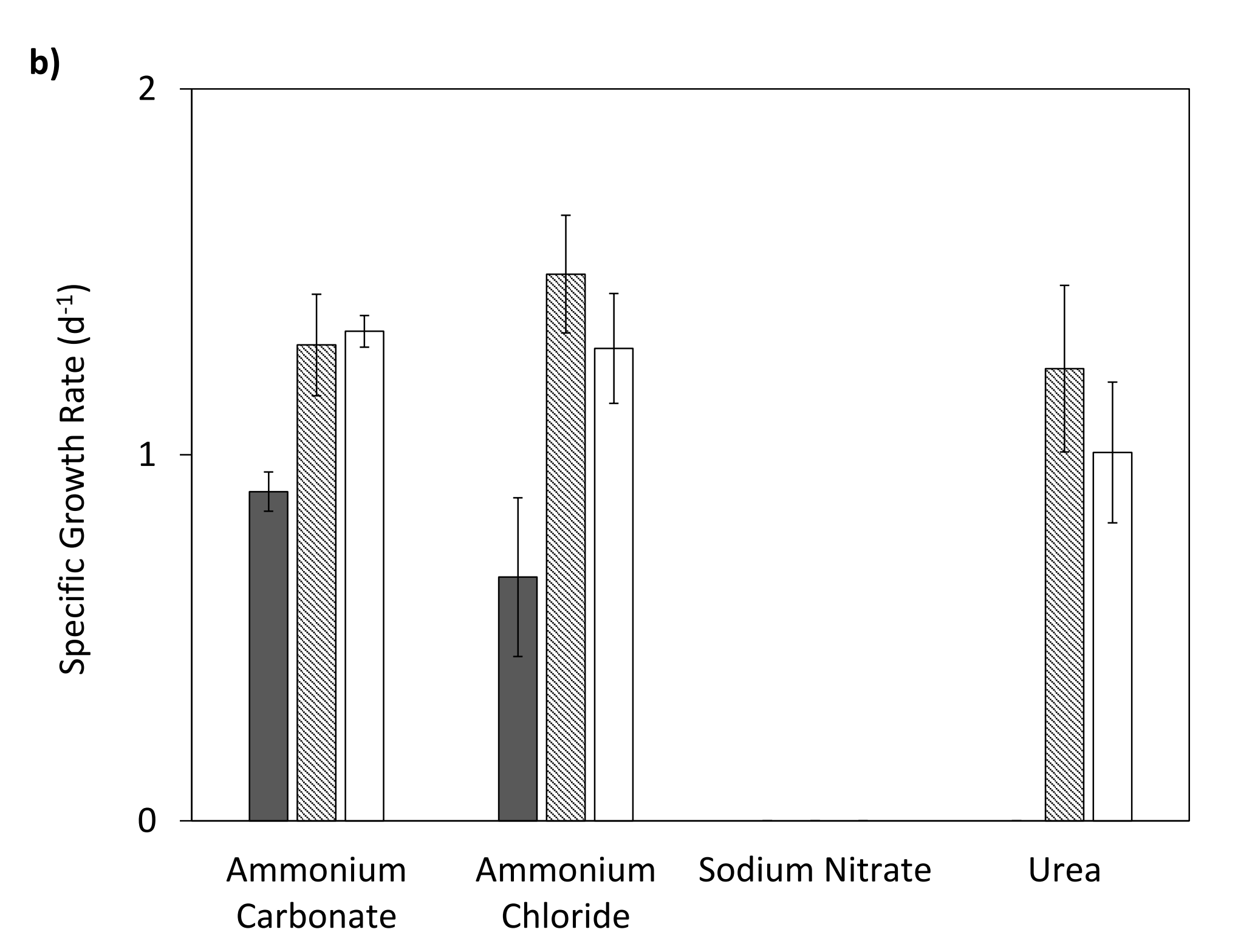

\section{Conclusions}

In vivo microplate batch cultures can be used to compare specific growth rates of microalgae containing chlorophyll-a.

This method can be used to determine the specific growth rate before significant pH changes in the media occur, making the method useful for comparison of various modes of nitrogen assimilation.

- It has been demonstrated that, at certain conditions, sodium nitrate is the most preferred nitrogen source and urea is the least favored nitrogen source for Chlorella vulgaris

- Auxenochlorella protothecoides demonstrated an acclimatization to urea, with no growth occurring in nitrate media in autotrophic conditions

- Nannochloropsis oculata showed a clear aversion for sodium nitrate as a nitrogen source.
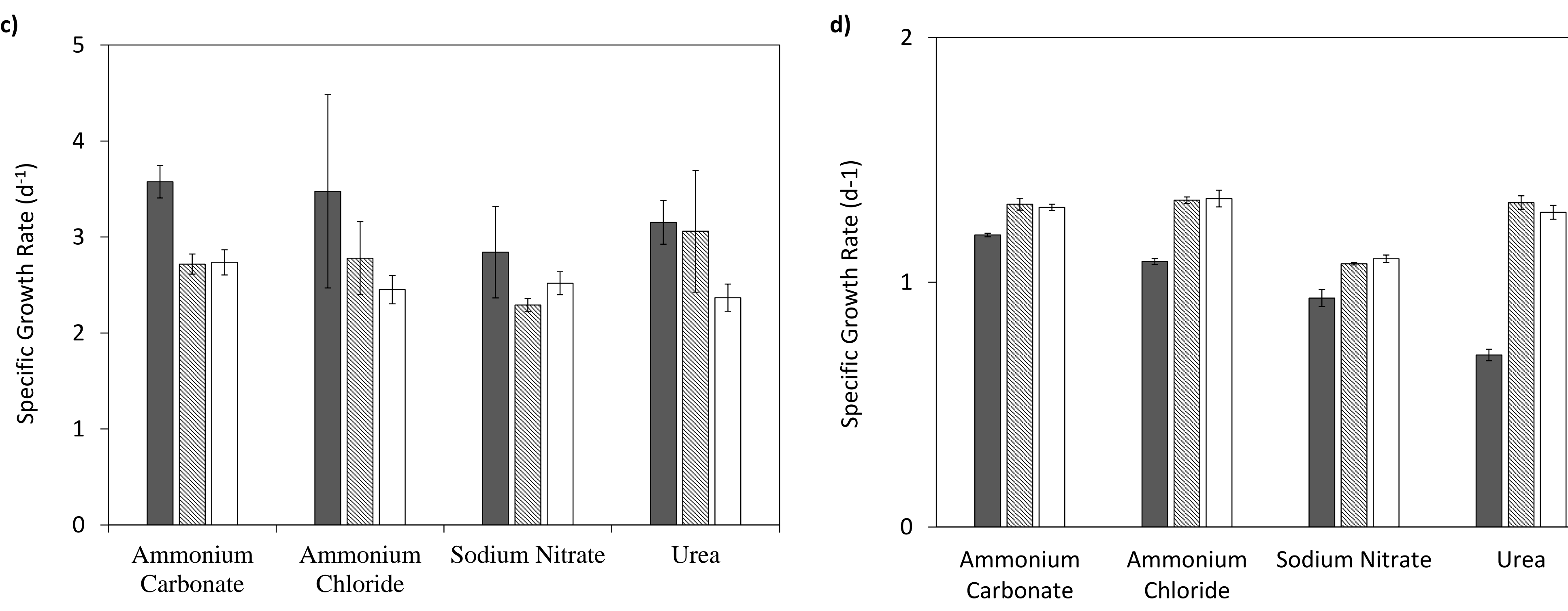

$\square$ 1st Cultivation $\quad \mathbb{Q}$ 2nd Cultivation $\quad \square$ 3rd Cultivation 